\title{
Work and the Role of the Dentist in the Intervention of Violence against Women Cases
}

\section{Dr. Ayşe Nurcan DUMAN}

Gazı University Faculty of Dentistry, Department of Prosthodontics

\section{Abstract}

Violence against women is a common issue that has existed in every time period regardless of education, age, ethnicity, religion, socio-economic condition and place. It is an important social and health issue that shakes the foundation of family, damages every member of the family. It has psychological, social and cultural layers and concerns every part of the society. According to the report published by WHO in 2013 , one out of every three women is subjected to physical or sexual violence. Violence against women which maintains its importance globally is also one of the important health and social issues in Turkey. In a 2014 study conducted in Turkey, $38 \%$ of the women -in other words, 4 out of every 10 women- between the ages of 15-59 reported that they had been subjected to violence by their current or former spouse/fiancée/boyfriend or by their close circle of family or friends. Among these violence victims, 6 out of every 10 women reported that they got injured 3 or more times. The fact that nearly half of these injuries required medical treatment reveals that violence poses a great threat to the physical health of women. In addition to this, the physical and the psychological trauma caused by violence might continue for a long time. Health services is one of the fundamental and primary services from which women who are subjected to or under risk of violence can get "help". However, violence against women is not an issue that can be overcome just by the healthcare personnel. It can be prevented by the joint efforts of institutions such as healthcare, social services, security, justice and ministries and by their interdisciplinary collaboration while the multitude of its reasons is taken into consideration. In this study, the importance of team work and the role and the responsibilities of the dentist in the intervention of violence against women are dealt with.

Keywords: Importance, team work, role, intervention, violence, women 